\title{
Los acuerdos de libre comercio: la nueva estrategia de Japón
}

$\mathrm{I}$ ntroducción

A principios de los años cincuenta, en plena etapa de reconstrucción de su economía tras su derrota en la segunda guerra mundial, Japón contaba con un ingreso per cápita menor al de países como Brasil, Malasia o Chile, una alta proporción de su fuerza de trabajo en la agricultura y un stock de capital e infraestructura seriamente dañados por la guerra. Empero, poseía una fuerza de trabajo altamente educada y capacitada en la industria, significativas diferencias en cuanto a productividad entre los diversos sectores productivos y un reconocido nivel de dirección y organización empresarial. Bastaron tres décadas para que Japón se convirtiera en la segunda economía más grande del mundo, con un ingreso per cápita sólo superado por Estados Unidos, Suiza y Noruega, para el año $2000 .{ }^{1}$ Sin embargo, desde finales de los años ochenta y principios de los noventa, la economía japonesa comenzó a caer en un prolongado período recesivo que le ha sido difícil superar, no obstante la aplicación de una serie de reformas económicas adoptadas ex profeso. Bajo estas circunstancias, y motivado por las experiencias un tanto exitosas de otros países con la firma de acuerdos de libre comercio, este país ha decidido unirse a la tendencia mundial hacia la integración de bloques comerciales, como una estrategia que pudiera representar el camino para impulsar las reformas y, al mismo tiempo, recuperar el crecimiento económico.

* Investigador del Departamento de Estudios del Pacífico de la Universidad de Guadalajara.

\section{Preparando el camino para la firma de acuerdos de libre comercio}

Si bien desde hace tiempo es considerado como una potencia regional por el tamaño y la importancia de su economía, Japón no ha logrado aún convertirse en el eje de los asuntos económicos y políticos de Asia, debido a que el país ha enfrentado diversos problemas internos y externos de carácter económico, político e histórico. Los obstáculos económicos y políticos se han presentado estrechamente entrelazados, en gran parte porque han surgido como resultado del funcionamiento del sistema político japonés y del poder que paulatinamente adquirieron ciertos grupos de interés, tal como los grandes conglomerados nacionales y multinacionales japoneses (conocidos como keiretsu) o los grupos de agricultores. Los obstáculos de carácter histórico están enraizados en las intrincadas relaciones que Japón fincó con los diversos países de Asia, antes y durante la segunda guerra mundial, las cuales no siempre se caracterizaron por ser amistosas y respetuosas con sus vecinos, de ahí el recelo y los resentimientos que algunos países mantienen hacia los japoneses hoy en día.

Todos estos elementos en conjunto de alguna $\mathrm{u}$ otra forma se han combinado para frenar las reformas económicas que el país necesita y ha intentado llevar a cabo, de ahí que los distintos esfuerzos del gobierno por reformar su sector agrícola, las redes de comercio al menudeo o los servicios financieros, en general no hayan prosperado como se esperaba. Para el gobierno ha sido sumamente difícil encontrar la manera de hacer que las reformas económicas funcionen y sean aceptadas por los mismos japoneses. Hasta muy recientemente parece ser que los 
líderes de Japón por fin han emprendido una nueva estrategia para impulsar las reformas económicas y recuperar la senda del crecimiento: la política comercial. Sin embargo, debido a una escrupulosa formulación y preparación de una serie de acuerdos comerciales totalmente inclinados a favor de los intereses de los grupos de poder internos, los políticos japoneses se han visto lentos en hacer realidad sus esfuerzos y capacidad de maniobra; y, algo por demás importante, pareciera que están perdiendo su poder de negociación ante sus potenciales socios comerciales.

Así, los japoneses han elegido como estrategia comercial la firma de acuerdos de libre comercio, en virtud de que éstos han tenido una gran aceptación en Europa y América y por las bondades que para muchos han demostrado, cuando menos en el renglón de fomento a las exportaciones. En sus bases, un acuerdo de libre comercio establece que cada uno de los países involucrados acepta eliminar, en determinado tiempo, todas las barreras comerciales en el comercio bilateral con su contraparte o entre los firmantes del mismo y también facilitar los flujos de inversión entre las partes.

\section{La experiencia de otros países con los acuerdos comerciales}

Algunos países se han adelantado ya a los japoneses y han acumulado una importante experiencia en materia de acuerdos de libre comercio. Estados Unidos, por ejemplo, signó en principio un acuerdo comercial con Canadá, para posteriormente ambos integrar a México en el Acuerdo de Libre Comercio de América del Norte (NAFTA, por siglas en inglés). Además, los estadounidenses tienen avanzadas negociaciones comerciales en lo individual con otros países de América Latina, y pretenden ir más allá al promover el establecimiento de un acuerdo de libre comercio que incluya a la gran mayoría de los países del continente: el Acuerdo de Libre Comercio de las Américas, conocido como ALCA. Por su parte, México es el país que más acuerdos de libre comercio ha firmado a nivel mundial (a la fecha cuenta con once acuerdos de libre comercio que incluyen a 32 países de América y Europa, en los cuales se han establecido períodos específicos de desgravación arancelaria para una gran variedad de productos). ${ }^{2}$

De igual forma, la Unión Europea se ha convertido en una amplia zona de libre comercio y ha estado expandiendo tales acuerdos con una gran variedad de países del norte de África, Europa del Este y América Latina. Mientras estos procesos ocurrían, los japoneses prácticamente no habían querido salir de sus terrenos y habían permanecido como simples espectadores; es hasta fechas recientes cuando aparecieron las primeras señales de integrarse a este movimiento. Aunque habría que aclarar que Japón optó por una política multilateral para la liberalización del comercio y la inversión, participando de manera activa en organismos como la Organización Mundial de Comercio (OMC) y APEC, relegando virtualmente a segundo plano la política bilateral de promoción de tratados comerciales.

\section{El primer acuerdo de libre comercio de Japón}

Fue hasta principios del año 2002 cuando Japón por fin decidió firmar su primer acuerdo bilateral de libre comercio con otro país: 
Singapur, una pequeña isla-ciudad-estado de apenas cuatro millones de habitantes ubicada en las proximidades con Malaisia, que además, al igual que en el caso de Japón, importa la gran mayoría de los insumos y alimentos para su población, pero en cambio, su economía está basada en una bien desarrollada industria manufacturera que paulatinamente ha ido especializándose en la informática y las telecomunicaciones, y se ha convertido en uno de los centros internacionales de servicios financieros y empresariales más importantes de Asia. ${ }^{3}$

Este acuerdo, denominado formalmente como "Acuerdo de Asociación Económica Japón-Singapur", constituye de hecho el primer paso de los japoneses en estos terrenos. Pero, ¿por qué Japón eligió a Singapur para un acuerdo comercial? En primer lugar, porque el gobierno de este último país desde hace varios años ha venido implementando una efectiva política que promueve un ambiente empresarial internacionalmente competitivo, lo que pudiera ser de gran utilidad para las empresas de Japón. En segundo lugar, porque las exportaciones de Singapur no incluyen muchos productos que son considerados como sensibles para los japoneses, como es el caso de los productos agrícolas o la industria automotriz.

Precisamente, una de las principales características del acuerdo con Singapur es que tiene un alcance muy amplio, puesto que no sólo incluye la disminución de las tarifas arancelarias en los bienes agrícolas y manufacturas, sino que también cubre otras áreas importantes como la liberalización de los servicios, la inversión, el movimiento de personas, entre otras. Otro aspecto interesante a resaltar del acuerdo de libre comercio con Singapur es que, durante el proceso de las negociaciones, los japoneses adoptaron como táctica principal concebir el acuerdo comercial en conjunto como una caja de soluciones para sus problemas, más que como un simple compromiso legal, para lo cual echaron mano de su reconocida experiencia empresarial en todo el proceso.
Esto constituye una visión totalmente distinta del tradicional pensamiento japonés sobre el comercio, en la cual su experiencia creativa abrió nuevas formas de pensamiento acerca de la política comercial y económica. Sin embargo, algunos opinan que el acuerdo de libre comercio Japón-Singapur fue un caso especial, puesto que existe la inquietud de que Japón no puede ir más allá de lo pactado con aquel país, debido a la fuerte influencia y poder político de sus agricultores y algunos grupos de poder.

Otros prospectos para firmar acuerdos de libre comercio con Japón, son México y Corea del Sur. La percepción que los mismos japoneses tienen es que, cualquiera que sea el primero en concretarse, un acuerdo comercial con estos países podría contribuir de manera importante a los esfuerzos del gobierno nipón por superar sus obstáculos estructurales y sacar adelante sus reformas institucionales. Lo interesante de estos potenciales acuerdos es que tanto México como Corea han insistido en incluir los productos agrícolas en el tratado con Japón, renglón que en el acuerdo JapónSingapur no requirió de mayores negociaciones por el hecho de ambos países son catalogados como importadores agrícolas netos; por lo que ahora han surgido algunas dificultades que tienen que ver con los intereses de los agricultores japoneses. Precisamente, una de las consecuencias de incluir al sector agrícola en un acuerdo de libre comercio es que los productores japoneses de arroz y de ganado, por ejemplo, tendrían que competir con base en sus propios recursos y su capacidad productiva, en lugar de seguir optando por la exclusión de todos los productos agrícolas.

¿En qué consiste el problema? En esencia, el acuerdo con Singapur de alguna forma dejó al descubierto el punto débil de los negociadores nipones en relación con las barreras comerciales en torno al casi sagrado sector agrícola japonés. Lo anterior por la razón de que tradicionalmente los agricultores japoneses han sido renuentes a permitir mayores concesiones a los gobernantes en turno sobre la protección a la agricultura. Ante 
estas circunstancias, los negociadores japoneses han procurado implementar algunas medidas para evitar que los distintos sectores de la economía no se vean afectados o limitados por intereses internos fundamentalmente opuestos a los acuerdos de libre comercio.

\section{La posibilidad de acuerdos de libre comercio con México y Corea del Sur}

Después de Singapur, todo parece indicar que el siguiente paso de Japón consiste en alcanzar un acuerdo comercial con México. El interés de los japoneses por México radica en que nuestro país se ha convertido en uno de los más activos promotores de acuerdos de libre comercio en el mundo (TLCAN, Unión Europea y varios países de América), por lo que gran parte de nuestro comercio está regido actualmente por reglas preferenciales convenidas con esas naciones. De ahí que otros países que no cuentan con un acuerdo comercial con México, enfrenten un arancel promedio de 16 por ciento sobre sus exportaciones a nuestro país, lo que significa una relativa desventaja respecto a los países que sí lo tienen. Esto se ha convertido en un problema real para las exportaciones japonesas y ha acrecentado el interés por lograr un acuerdo de libre comercio entre Japón y México.

Sin embargo, la importancia de elegir a México es un tanto relativa y pareciera obedecer más bien a otros intereses, por ejemplo, si se toma en cuenta que alrededor de 20 por ciento de las importaciones japonesas provenientes de México son agrícolas y que, de acuerdo con los lineamientos de la OMC, un acuerdo de libre comercio tiene que cubrir de manera sustancial todo el comercio, lo cual es interpretado como más de 90 por ciento del intercambio comercial. Por lo tanto, Japón no puede excluir a su sector agrícola en un posible acuerdo comercial con nuestro país; tiene que asumir el reto de eliminar o disminuir de manera sustancial las tarifas que aplica en una gran parte de los productos agrícolas, lo que forzosamente tendría efectos significativos sobre su estructura de producción y mercados agrícolas.

Las tarifas impuestas por México sobre las importaciones que provienen de países con los cuales no tiene un acuerdo comercial es un punto que en los últimos años cada vez más ha preocupado y llamado la atención de los japoneses, quienes ante estas circunstancias seguramente han evaluado ya todos los potenciales beneficios de un acuerdo de libre comercio entre ambos países. Incluso en el caso de la agricultura, las cosas son un poco más fáciles de lo que podría esperarse si se toma en cuenta que la producción agrícola mexicana, debido a la ubicación geográfica del país, tiende a ser complementaria más que competitiva para la agricultura japonesa. Además, algunas de las tarifas de Japón sobre los bienes mexicanos son menores de 5 por ciento y podrían ser fáciles de eliminar.

Para el gobierno japonés, estos aspectos podrían representar elementos a su favor para negociar un acuerdo de libre comercio con México. Por supuesto, antes serán necesarios esfuerzos políticos serios para superar la resistencia en el sector agrícola de Japón a fin de avanzar en los intereses nacionales más amplios. De esta forma, la actual posición comercial de México en el mundo representa para Japón una valiosa oportunidad de poner a prueba su capacidad política para consolidar su reforma estructural.

Un tercer país que Japón tiene en mente para la probable firma de un acuerdo comercial es Corea del Sur. En realidad los coreanos siempre han sido una prioridad para los japoneses, de hecho es la opción más natural en virtud de tres condiciones fundamentales: la estrecha cercanía entre ambos, los dos son aliados estratégicos de Estados Unidos y son miembros de la Organización para la Cooperación y Desarrollo Económicos (OCDE). Asimismo, la experiencia de los coreanos con su programa de reformas económicas, posterior a la crisis financiera de 1997, constituye una valiosa experiencia de la cual podrían aprender mucho los japoneses. 
Sin embargo, en contraposición a estos factores favorables para un acuerdo de libre comercio entre Japón y Corea del Sur, hay un obstáculo mayor - al igual que con otros países de la región- que tiene que ver con un antagonismo histórico profundamente enraizado. Este es el caso de los coreanos, debido a que su territorio fue convertido en una colonia japonesa a principios del siglo pasado. No obstante, en la actualidad parece ser que las heridas están comenzando a cerrarse, cuando menos eso es lo que han estado procurando sus respectivos gobiernos; además, actualmente los sentimientos de los coreanos en general parecen ser más favorables con los japoneses de lo que antes eran. Incluso, podría afirmarse que Corea del Sur disfruta ahora de una mejor posición para pedirle a Japón que enfrente los problemas de su pasado y, en este proceso, llegue a ser más confiable y aceptado en la región. Por lo que el significado de un posible acuerdo comercial entre los dos países no estaría limitado exclusivamente a beneficios económicos, necesariamente tendría que tener implicaciones sociales, políticas e históricas más amplias.

Hoy en día es difícil prever en qué términos Japón concretará al final un acuerdo de libre comercio con México y Corea del Sur, en todo caso, lo que habría que señalar es que los negociadores japoneses han diseñado este proceso de manera muy cuidadosa, es decir, han ido avanzando paso a paso y procurando las mejores condiciones posibles para su país. Lo que es un hecho es que para los japoneses ningún reto particular es demasiado pesado o políticamente insalvable, ya que para ellos cada acuerdo potencial representa mayores beneficios que podrían ayudar a superar la inevitable resistencia interna.

\section{Conclusiones}

Si bien los acuerdos de libre comercio no son en realidad una solución completa para todos los problemas económicos de Japón, cabe la posibilidad de que la exitosa experiencia de otros países con esos mecanismos pueda cambiar las expectativas de los japoneses. De igual forma se tiene la esperanza de que con tales acuerdos se pueda mejorar el ambiente político, al abrirse nuevas oportunidades para avanzar en las reformas institucionales y un mayor grado de apertura de la economía, lo que sin duda despejaría el camino a Japón para asumir un papel más protagónico en los asuntos económicos y políticos de Asia.

\section{Notas}

1 Medido en dólares internacionales. World Bank, 2002 World Development Indicators, Washington, D.C.

2 Ver el trabajo de Jorge Sebastian Roberts, The Reasons for Mexico's Trade Liberalization, EU: University of Washington, Seatle, mayo de 2001.

3 Véase el trabajo de Chia Siow Yue, "Singapore's trade and development strategy and ASEAN economic cooperation, with special reference to the ASEAN common approach to foreign economic relations" ASEAN in a Changing Pacific and World Economy, Australasian National University Press, USA, 1980, pp. 241-279.

\section{Bibliografía}

The Brookings Institution, "How Trade Agreements can Reform Japan", Center for Northeast Asian Policy Studies, Washington D.C., 10 de julio de 2002.

R. Glenn Hubbard, "Impediments to Growth in Japan", Washington D.C., 8 de abril de 2002.

Michael J. Mandel, "Economic Trends: A Lesson from Japan”, Business-week, 4 de marzo de 2002.m? 